\title{
Wind Tunnel Experiment on Sand Blocking Efficiency of Shelterbelts in Different Configurations
}

\author{
Jingwen $\mathrm{Li}^{1}$, Suocheng Dong ${ }^{1, *}, \mathrm{Yu} \mathrm{Li}^{1}$ \\ ${ }^{1}$ Institute of Geographic Sciences and Natural Resources Research, Chinese Academy of Sciences, Beijing, \\ China \\ "Corresponding author. Email: dongsc@igsnrr.ac.cn
}

\begin{abstract}
Shelterbelts are of great significance to reducing wind and sand disasters and improving and restoring the ecological environment in arid areas. In order to optimize the configuration of shelterbelts in arid areas, this study used Pinus sylvestrwasvar. Mongolica and Haloxylon ammodendron as research objects, and designed two forest belt models of No. 1 and No. 2. through wind tunnel tests, analyze the sediment transport, wind erosion rate, and dust distribution characteristics of belts with different configurations. The results show: (1) both soil sediment transport and wind erosion rate increased with the increase of wind speed. Under low wind speeds, the No. 2 forest belt had the least amount of sediment; under high wind speeds, the 20-year-old forest belt of the No. 1 belt had the smallest amount of sediment; (2) Under the same wind speed, the 20-year-old forest belt had the lowest soil wind erosion rate, and the 5-year-old forest belt had the highest soil wind erosion rate. (3) The 20year-old of No. 1 belt had a stronger ability to block sand, and the amount of dust fall at each point behind the belt was smaller than that of the bare ground. The research results can provide a theoretical basis for the optimization of the ecological environment in the arid area of the Mongolian Plateau.
\end{abstract}

Keywords: Wind tunnel test, shelterbelt height, shelterbelt density, sand blocking efficiency

\section{INTRODUCTION}

Desertification is one of the most serious environmental and socio-economic problems in the southern Mongolian plateau [1]. Windbreak and sand fixation forest can effectively reduce wind, block aeolian sediment transport and change aeolian landforms, as well as reduce the soil erosion rate by directly covering part of the land surface $[2 ; 3]$. Therefore, it is of great significance to build the best shelterbelt on the basis of limited water and soil resources carrying capacity, which is effective for relieving wind and sand disasters and preventing sedimentation.

The current research on the benefits of shelterbelts focuses on the evaluation of ecological benefits at the stand scale, and most of them are wind protection benefits, moisture, soil, heat, and other aspects $[4 ; 5 ; 6 ; 7]$. Among them, the observation of protection benefits is generally limited to a certain period of time [8; 9], but there is little evaluation of the overall benefits for a long time. The comparison of the sand-fixing ability of arbor and shrub protection forests and the study of the sand blocking effect of the protection forests with the change of forest age are few reports.

Therefore, in order to strengthen the ecological management of the desert areas of the Mongolian Plateau, it is very necessary to use the wind tunnel simulation method to systematically study the deployment mode of the shelterbelt on the basis of analyzing the research status of domestic and foreign shelterbelts and summing up the past experience and lessons. The optimal allocation of shelterbelts on the Mongolian Plateau provides new ideas and theoretical basis.

\section{MATERIALS AND METHODS}

\subsection{Experimental material}

The most important thing in wind tunnel simulation is to ensure that the model is the same shape and proportional to the actual object. The use of dimensionless physical quantities ensures that when analyzing the relationship between research 
results, the quantities themselves are no longer examined, but the values of the physical quantities are compared. Based on the above criteria and considering the influence of wind tunnel boundary layer on the experimental accuracy, Pinus sylvestrisvar. Mongolic and haloxylon ammodendron in 5, 10 and 20 years were taken as the research objects, and the design model is designed at 1:50. Both Pinus sylvestris var. Mongolic and haloxylon ammodendron were 10 rows (Table 1).

Table 1. Parameters of shelterbelts model with different configurations

\begin{tabular}{|c|c|c|c|c|c|c|c|}
\hline Shelterbelts & $\begin{array}{l}\text { Shelterbelts } \\
\text { Number }\end{array}$ & Rows & $\begin{array}{c}\text { Length } \\
\text { (cm) }\end{array}$ & $\begin{array}{l}\text { Width } \\
\text { (cm) }\end{array}$ & $\begin{array}{l}\text { Height } \\
\text { (cm) }\end{array}$ & $\begin{array}{c}\text { Row } \\
\text { Spacing } \\
\text { (cm) }\end{array}$ & $\begin{array}{l}\text { Line } \\
\text { Spacing } \\
\text { (cm) }\end{array}$ \\
\hline \multirow{6}{*}{$\begin{array}{c}\text { Pinus } \\
\text { sylvestris } \\
\text { var.mongolic } \\
\text { Shelterbelts }\end{array}$} & 1a1 & 10 & 150 & 108 & 2 & 12 & 12 \\
\hline & $1 \mathrm{a} 2$ & 10 & 150 & 108 & 8 & 12 & 12 \\
\hline & $1 \mathrm{a} 3$ & 10 & 150 & 108 & 40 & 12 & 12 \\
\hline & 1b1 & 10 & 150 & 162 & 2 & 18 & 18 \\
\hline & $1 \mathrm{~b} 2$ & 10 & 150 & 162 & 8 & 18 & 18 \\
\hline & $1 \mathrm{~b} 3$ & 10 & 150 & 162 & 40 & 18 & 18 \\
\hline \multirow{6}{*}{$\begin{array}{l}\text { Haloxylon } \\
\text { ammodendron } \\
\text { Shelterbelts }\end{array}$} & $2 \mathrm{a} 1$ & 10 & 150 & 81 & 2 & 9 & 9 \\
\hline & $2 \mathrm{a} 2$ & 10 & 150 & 81 & 4 & 9 & 9 \\
\hline & $2 \mathrm{a} 3$ & 10 & 150 & 81 & 8 & 9 & 9 \\
\hline & $2 \mathrm{~b} 1$ & 10 & 150 & 108 & 2 & 12 & 12 \\
\hline & $2 \mathrm{~b} 2$ & 10 & 150 & 108 & 4 & 12 & 12 \\
\hline & $2 \mathrm{~b} 3$ & 10 & 150 & 108 & 8 & 12 & 12 \\
\hline
\end{tabular}

\subsection{Experimental setting}

The shelterbelts models were placed at the specified position in the experimental section. In front of the models, $50 \mathrm{~kg}$ of desert sand with a length of $1 \mathrm{~m}$, a width of $1.8 \mathrm{~m}$ and a thickness of 2 $\mathrm{cm}$ was laid as the sand source. At the rear of the models, a row of collecting sandboxes were placed every $3 \mathrm{~m}$, and a total of 4 rows were placed, one was placed every $40 \mathrm{~cm}$, and 3 were discharged per row (Figure 1).

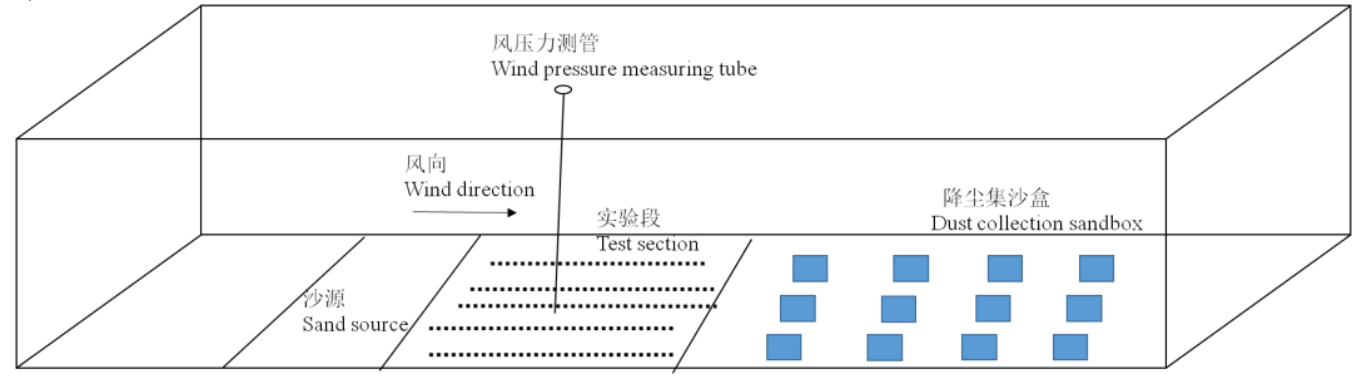

Figure 1. The layout of the sand fixation experiment model

The experimental wind speed was set as $6 \mathrm{~m} / \mathrm{s}, 8$ $\mathrm{m} / \mathrm{s}$ and $10 \mathrm{~m} / \mathrm{s}$ respectively, in which $6 \mathrm{~m} / \mathrm{s}$ blew for $8 \mathrm{~min}, 8 \mathrm{~m} / \mathrm{s}$ blew for $6 \mathrm{~min}, 10 \mathrm{~m} / \mathrm{s}$ blew for $4 \mathrm{~min}$. For each set of experiments, the sand collection weight in each collecting sandboxes and the sand source weight after blowing were recorded. The control experiment was the erosion and accumulation index of the dust under the condition of the same weight of the sand source without shelterbelts models.

\section{RESULTS}

\subsection{Sediment discharge}

The sediment discharge of Pinus sylvestris var.mongolic shelterbelts and haloxylon ammodendron shelterbelts increases with the increase of wind speed. The sediment discharge of No. 1 forest shelterbelt at $6 \mathrm{~m} / \mathrm{s}$ wind speed decreases with the increase of shelterbelt height. The sediment discharge of 5-year-old No. 1 shelterbelt within $8 \mathrm{~min}$ was $1.26 \mathrm{~g}$, which was $0.75 \mathrm{~g}$ and $1.01 \mathrm{~g}$ more than that of 10-year-old and 20-year-old No.1 shelterbelts, respectively; Under the wind speed of $6 \mathrm{~m} / \mathrm{s}$, the sediment load of the 5-year-old No.2 belt was $0.34 \mathrm{~g}$, which was $16.25 \%$ and $49.62 \%$ less than that of the 10 -year-old forest belt and the 20-year-old forest belt respectively; Under the wind speed of $8 \mathrm{~m} / \mathrm{s}$, the amount of sand transported by the No.2 belt decreased as the height increased. Comparing the two types of belts No. 1 and No. 2, it can be seen that when the wind speed was $6 \mathrm{~m} / \mathrm{s}$, the 5 -year-old No. 1 shelterbelt had the largest amount of sand, the 20- 
year-old No. 2 shelterbelt had the second place. The sand transport was the least at $0.25 \mathrm{~g}$; when the wind speed was $8 \mathrm{~m} / \mathrm{s}$, the sand transport in the 5-year-old and 10-year-old No.1 shelterbelt were much greater than that of the No.2 shelterbelt of the same age; when the wind speed was $10 \mathrm{~m} / \mathrm{s}$, the amount of sand transported by the 20-year-old haloxylon ammodendron shelterbelt was $6.40 \mathrm{~g}$, and the 20-yearold Pinus sylvestrwasvar.

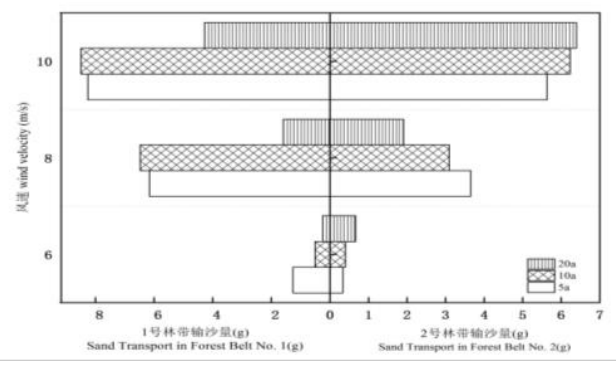

Figure 2. Soil sediment transport in a single forest with different configurations
Mongolic shelterbelt had the least amount of sand at $4.28 \mathrm{~g}$, which was equivalent to that of the 5-year-old haloxylon ammodendron shelterbelt (Figure 2).

\subsection{Soil wind erosion rate}

Different configurations of Pinus sylvestrwasvar.mongolic shelterbelt and haloxylon ammodendron shelterbelt can effectively reduce soil wind erosion. The soil wind erosion rate of forest belts at a wind speed of $6 \mathrm{~m} / \mathrm{s}$ was the smallest, followed by wind speeds of $8 \mathrm{~m} / \mathrm{s}$, and the soil erosion rate of forest belts at a wind speed of $10 \mathrm{~m} / \mathrm{s}$ was the largest; under the same wind speed, the 20-year-old forest belt has the smallest soil wind erosion rate. High-density forest No. 1 b1 forest belt had the highest average soil wind erosion rate, which was $3.20 \mathrm{~g} \cdot \mathrm{m}-2 \cdot \mathrm{min}-1$. Compared with the wind speed of $6 \mathrm{~m} / \mathrm{s}$, the soil wind erosion rate of the bare ground was 11.50 times and 11.79 times of the wind erosion rate of the No. 1shelterbelt and the No. 2 shelterbelt.

Table 2. Soil wind erosion rate in a single forest belt in different configurations

\begin{tabular}{|c|c|c|c|c|c|}
\hline \multirow[t]{2}{*}{ Forest Type } & \multicolumn{3}{|c|}{$\begin{array}{l}\text { Soil Wind Erosion Rate at Different Wind } \\
\text { Speeds }(\mathrm{g} \cdot \mathrm{m}-2 \cdot \min -1)\end{array}$} & \multirow{2}{*}{$\begin{array}{c}\text { Average Soil Wind } \\
\text { Erosion Rate } \\
(\mathrm{g} \cdot \mathrm{m}-2 \cdot \mathrm{min}-1)\end{array}$} & \multirow[t]{2}{*}{ Reduction Ratio } \\
\hline & $6(\mathrm{~m} / \mathrm{s})$ & $8(\mathrm{~m} / \mathrm{s})$ & $10(\mathrm{~m} / \mathrm{s})$ & & \\
\hline $\mathrm{CK}$ & 2.42 & 5.36 & 8.04 & 5.28 & - \\
\hline 1a1 & 0.49 & 2.58 & 5.13 & 2.73 & 0.48 \\
\hline $1 \mathrm{a} 2$ & 0.18 & 2.18 & 4.23 & 2.20 & 0.58 \\
\hline $1 \mathrm{a} 3$ & 0.06 & 0.86 & 3.21 & 1.38 & 0.74 \\
\hline $1 \mathrm{~b} 1$ & 0.29 & 3.21 & 6.09 & 3.20 & 0.39 \\
\hline $1 \mathrm{~b} 2$ & 0.14 & 2.55 & 5.49 & 2.73 & 0.48 \\
\hline $1 \mathrm{~b} 3$ & 0.10 & 0.46 & 2.14 & 0.90 & 0.83 \\
\hline $2 \mathrm{a} 1$ & 0.13 & 1.65 & 4.53 & 2.10 & 0.60 \\
\hline $2 \mathrm{a} 2$ & 0.11 & 1.11 & 3.85 & 1.69 & 0.68 \\
\hline $2 \mathrm{a} 3$ & 0.10 & 0.20 & 3.22 & 1.18 & 0.78 \\
\hline $2 \mathrm{~b} 1$ & 0.26 & 1.47 & 3.94 & 1.89 & 0.64 \\
\hline $2 \mathrm{~b} 2$ & 0.14 & 1.39 & 3.82 & 1.78 & 0.66 \\
\hline $2 \mathrm{~b} 3$ & 0.08 & 1.38 & 3.46 & 1.64 & 0.69 \\
\hline
\end{tabular}

Comparing the average value of soil wind erosion rate under three wind speeds, we found the average erosion reduction capacity of No.1 forest belt was greater than $75 \%$ except for No.1 a3 and No.1 b3 forest belts. The average erosion reduction capacity of No.1 forest belts in other configurations was between $40 \%$ and $60 \%$. The average erosion reduction capacity of No. 2 forest belt exceeds $60 \%$, and No.2 a2, which had the highest density in 20 years, had the largest reduction of $78 \%$.

\subsection{Dust fall distribution characteristics}

In order to visually compare the difference between the distribution characteristics of dust fall after different shelterbelts and the dust falls of the CK group on the bare surface, the dust fall at different locations in the CK group was used as a horizontal reference level to plot the dust fall distribution and erosion accumulation after different configurations of shelterbelts. Compared with CK, the amount of dust fall behind No.1 Pinus sylvestrwasvar.mongolic shelterbelt increased with the increase of the belt height. The dust fall after the 20-year-old Pinus sylvestrwasvar.mongolic shelterbelt was less than 
that of the CK group, and the dust fall on the left $3 \mathrm{~m}$ behind the belt was the least. In No. 2 belt, the 5 -yearold Haloxylon belt increased with the distance, and the dust fall gradually increased. The post-belt dust fall of the 10-year-old and 20-year-old forest belts had similar changes, and both increase with the increase of distance. Compared with No.1 and No.2 belts of the same forest age, the horizontal distribution of dust fall after the two forest belts was more even, but the amount of dust fall in the same position in the 20-year-old Pinus sylvestrwasvar.mongolic shelterbelt was significantly less than that of the No.2 belts (Figure 3).

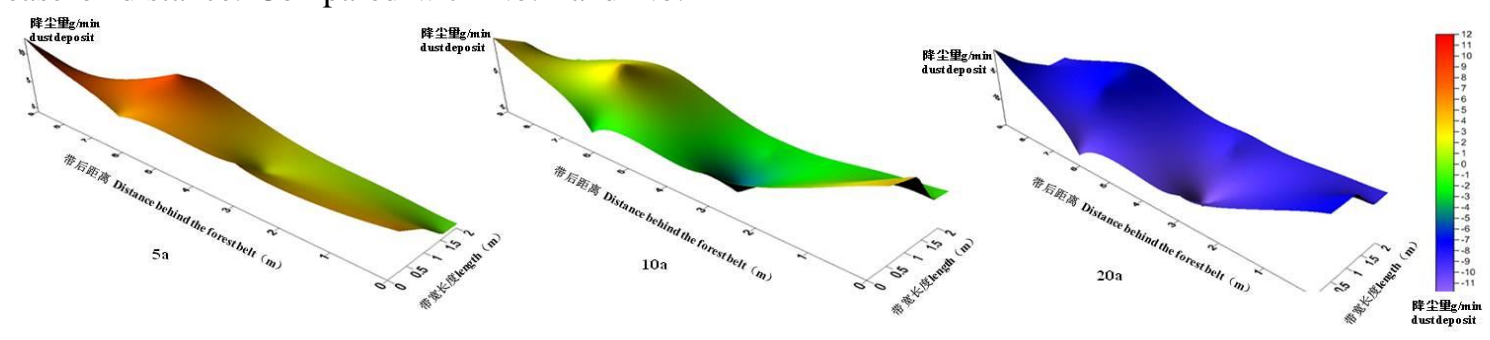

(a) Dust fall distribution after forest belt 1

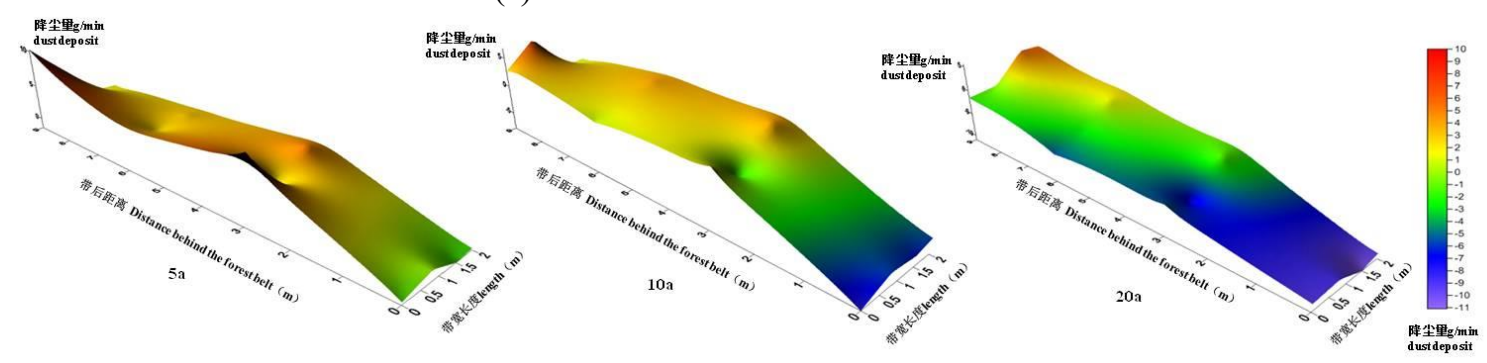

(b) Dust fall distribution after forest belt 2

Figure 3. Distribution characteristics of dust deposit in pure forest belts with different configuration

\section{CONCLUSIONS}

1. Both soil sediment transport and wind erosion rate increased with the increase of wind speed. sand saltation was the most active way of sand encroachment.

2. Under low wind speeds, the No. 2 forest belt had the least amount of sediment; under high wind speeds, the 20-year high forest belt of the No. 1 belt had the smallest amount of sediment;

3. Under the same wind speed, the 20-year high forest belt had the lowest soil wind erosion rate, and the 5-year high forest belt had the highest soil wind erosion rate. The higher the wind speed, the more obvious the effect of high forest belts on reducing soil wind erosion.

4. Dust fall increased with distance after different configurations of forest belts, but the increase in tall forest belts was smaller than that of low forest belts. The 20-year high Pinus sylvestris var. Mongolica forest had the strongest ability to block sand.

\section{ACKNOWLEDGMENTS}

The work was supported by the Science \& Technology Basic Resources Investigation Program of China (2017FY101304), and National Natural Science Foundation of China (Grants 41911530103, 41701639). Key deployment project of Chinese Academy of Sciences (ZDRWZS201812).

\section{REFERENCES}

[1] Zhao, Wenzhi, et al.2008. Shielding effect of oasis-protection systems composed of various forms of wind break on sand fixation in an arid region: A case study in the Hexi Corridor, northwest. China. Ecological Engineering 33.2: 119-125.

DOI: https://doi.org/10.1016/j.ecoleng.2008.02.010

[2] Cheng, Hong, et al.2018. Wind tunnel study of airflow recovery on the lee side of single plants. Agricultural and Forest Meteorology 263: 362372.

DOI: https://doi.org/10.1016/j.agrformet.2018.08.025 
[3] Gillies, John A., Joanna M. Nield, and William G. Nickling. 2014. Wind speed and sediment transport recovery in the lee of a vegetated and denuded nebkha within a nebkha dune field. Aeolian Research 12: 135-141. DOI: https://doi.org/10.1016/j.aeolia.2013.12.005

[4] Bagley WT. 2000.Agroforestry and windbreaks. Agriculture Ecosystems and Environment 22-23. DOI: https://doi.org/10.1016/01678809(88)90047-3

[5] Ritchie K A. Shelterbelt plantings in semi-arid areas. Agriculture Ecosystems \& Environment, 2010 , 22:425-440.

DOI: https://doi.org/10.1016/0167-8809(88)90037-0

[6] Bitog JP, Lee IB, Hwang HS, et al. 2015.A Wind tunnel study on aerodynamic porosity and windbreak drag. Forest Science and Technology
7(1):8-16.

DOI: https://doi.org/10.1080/21580103.2011.559939

[7] Wang H. Takle. 2005. A numerical simulation of boundary-layer flows near shelterbelts. Boundary-Layer Meteorology 75(1): 141-173. DOI: https://doi.org/10.1007/BF00721047

[8] Zhang, Shuai, et al.2018. Effect of straw checkerboards on wind proofing, sand fixation, and ecological restoration in shifting sandy land. International journal of environmental research and public health 15.10: 2184. DOI: https://doi.org/10.3390/ijerph15102184

[9] Bao YF, Ding GD,Wu B,et al. 2013.Study on the wind-sand flow structure of windward slope in the Mu Us Desert,China. Jounal of Food, Agriculture \& Environment 11(2):1449-1454. 